\title{
Alteration of Iron Metabolism of Elite Female Distance Runners
}

\section{in Intensity Training}

\author{
Bayar Tsinggel \\ Physical Education Department, Inner Mongolia Agricultural University \\ Hohhot 010018, China \\ E-mail: bayar@126.com \\ Bao Dagula \\ Physical Education Department, Inner Mongolia Nationality College \\ Hohhot 010051, China
}

\begin{abstract}
The hemoglobin $(\mathrm{Hb})$, serum Iron (SI), serum ferritin, serum transferrin (Tr), serum transferrin receptor (sTfR) concentration, Erythrocyte hemoglobin distribution width(RDW) and erythropoietin(EPO) in adults are suggested to provide a sensitive measure of iron depletion and the serum ferritin (Ferr) concentration is able to indicate the entire range of iron status, from iron deficiency to iron overload. However, little is known about those indexes in elite female distant runners. The objective of this study was to determine the above indexes in intensity training of 8 elite female distant runners two months ahead of national competition. Result showed that $\mathrm{Hb}$ concentration decreased in second sampling point and then recovered; SI concentration firstly decreased then increased, but it was not significant; $\operatorname{Tr}$ concentration, RDW and EPO level increased in second sampling point then fell to baseline; there was no significant difference in Ferr and sTfR concentration. It can be concluded that due to intensity training, iron metabolism in the initial stage of training was disturbed and then modulated in following training phase.
\end{abstract}

Keywords: Hemoglobin, Transferrin, Transferrin receptor, Iron metabolism, Erythropoietin

\section{Introduction}

The concentration of hemoglobin is of great significance for intensity training, and for the specialized quality of endurance athletes. The concentration of athletes' hemoglobin is influenced by nutrition, sport load and rest during training and competition. The iron metabolism influences the synthesis of hemoglobin; athletes need more iron than the ordinary person, and iron requirement changes with the training time, intensity and environmental factors (Feng, 2003, P.56-64). Much training will accelerate the iron metabolism and influence the iron balance of body. It is easy for athletes to get sport anemia, accordingly, athletes' competitive ability will be influenced. The main reason for sport anemia is the low synthesis of hemoglobin because of iron deficiency. In this paper, we studied the indexes relating to iron metabolism of elite female distance runners, with the purpose of finding out the changing rule of these indexes and providing evidence for the evaluation and training control of athletes.

\section{Materials and methods}

\subsection{Research object}

Study on the indexes of eight female middle-distance runners in intensity training two months before competition. Sampling was carried out in the morning of adjusting day, and athletes were not in menses. The age of athlete is $23.5 \pm 2.3$ year, the stature is $166.2 \pm 5.8 \mathrm{~cm}$, the weight is $54.8 \pm 8.9 \mathrm{~kg}$, the training life is $6.7 \pm 1.8$ year, and percentage body fat is $15.2 \pm 5.5 \%$.

\subsection{Methods}

\subsubsection{Training plan}

Training cycle was one week, specifically, large intensity training on Monday, mixed aerobic training on Tuesday and Wednesday, aerobic training on Thursday, large intensity training on Friday and aerobic training on Saturday and Sunday. Large intensity training would be agilely arranged in the aspects of distance and rest; the plan would be changed according to the situation of athletes. 


\subsubsection{Sampling and preservation}

Blood sample was taken every two weeks, totally four times. At 7:00-7:30, athletes were hollow, $1 \mathrm{~mL}$ whole blood was taken with EDTA, and $4 \mathrm{~mL}$ whole blood was taken with general vacuum tube, the blood with EDTA was used in blood count right away, the other tube of blood will be placed for 30 minutes, two tubes of blood were centrifuged at 3000 $\mathrm{rpm}$ for 20 minutes, the serum was isolated and stored at -20 centigrade for the following experiment.

\subsubsection{The test of indexes}

Blood counting instrument (Sysmex KX-2IN, Japan) was used to test blood routine; reagent kit for determining serum iron from Beijing Zhongsheng Biotech Engineering Corporation was used, wavelength was 540nm, temperature was 37 centigrade, and reaction was automatically finished with AG II System biochemical analyzer (Landmark Scientific Inc. Greensboro, North Carolina USA); method of radioimmunoassay was used to test the serum iron, antigen was labeled with ${ }^{[125]}$ I and the antigen that would be tested can competitively interact with specific antibody, which is the principle of serum iron test. Serum ferritin RIA kit was provided by Beijing North Institute of Biological Technology, reaction was done at 37 centigrade for 1 hour, the coefficient of variation within a single assay and between assays were $6.0 \%$ and $12 \%$ respectively. The impulse number of compound was counted on SN-6958 gamma counter (Shanghai Institute of A-energy). ELISA (Enzyme Linked Inmunosorbent Assay, ELISA) was used to detect the concentration of serum transferrin (Tr), serum transferrin receptor (sTfR). The antigen or antibody was solidified and labeled by enzyme, when the substrate of enzyme was added, the substrate would be catalyzed by enzyme as colored product, and the amount of product would have direct relationship with the target. The serum transferrin kit was provided by Bethyl Company (Bethyl Laboratory, Inc), the coefficient of variation within a single assay was less than 7\%, and the coefficient of variation between assays was less than $10 \%$. Serum transferrin receptor kit was provided by R\&D Company (R\&d Systems, Inc), the coefficient of variation within a single assay was less than $5 \%$, and the coefficient of variation between assays was less than 12\%. RT-6000 enzyme-labeled instrument (Rayto Life and Analytical Sciences Co., Ltd. USA) and RT-3000 well wash were used, OD value was got according to the manufacturer's protocols and automatically printed; Chemiluminescent Method was used to determine the erythropoietin, kit was provided by Tianjin Data Processing Center (DPC), Immulite 1000 (DPC, Tianjin Co., Ltd.) was used, the coefficient of variation within a single assay was less than $5 \%$, and the coefficient of variation between assays was less than $9 \%$.

\subsubsection{Data analysis}

K-S method was used to determine if various indexes of serum fit the normal distribution, if so, single element repeated measurement variance analysis was used to make a $1 \times 4$ treatment. Mauchly's test of sphericity was done firstly, if the hypothesis is right, univariate variance analysis will be used to analyze the result, on the contrary, univariate variance analysis was used to correct the result. If the data don't fit the normal distribution, Friedman test was used to compare the difference between assays. Data were represented as average \pm standard value, significance level $\mathrm{P}<0.05$, great significance level $\mathrm{P}<0.01$.

\section{Results}

3.1 Content variation of red blood cell, hemoglobin, pressure and volume of blood cell, Erythrocyte hemoglobin distribution width $(R D W)$, serum iron and serum ferritin.

As shown in table 1 that, the red blood cell, pressure and volume of blood cell, serum iron and serum ferritin didn't change much, the content of hemoglobin decreased 20 days after training $(\mathrm{P}<0.05)$, and when 40 days and 60 days after training, the content of hemoglobin increased compared with that 20 days after training $(\mathrm{P}<0.05)$, but changed little compared with the situation before training $(\mathrm{P}>0.05)$. RDW 20 days after training was higher than that before training $(\mathrm{P}<0.05)$, and RDW 40 days and 60 days after training was much lower than that 20 days after training $(\mathrm{P}<0.05)$.

\subsection{The variation of athletes' serum transferrin}

Repeated measurements variance analysis revealed that the content of serum transferrin 20 days after training is much higher than that before training $(\mathrm{P}<0.05)$ as shown in Figure 1.

\subsection{The variation of athletes' serum transferrin receptor content}

Serum transferrin receptor didn't change much in the training as shown in Figure 2.

\subsection{The variation of athletes' erythropoietin}

Friedman variance analysis showed that the content of erythropoietin 40 days and 60 days after training were higher than that 20 days after training $(\mathrm{P}<0.05)$, but it didn't change much compared with that before training $(\mathrm{P}>0.05)$ as shown in Figure 3.

\section{Results and discussion}

The red blood cell and pressure and volume of blood cell didn't change during the training. The amount of hemoglobin 20 days after training decreased compared with the amount before training $(\mathrm{P}<0.05)$, the amount of hemoglobin 40 days 
and 60 days after training increased compared with the amount 20 days after training $(\mathrm{P}<0.05)$, but there was no significant difference when compared with the situation before training $(\mathrm{P}>0.05)$. It is proved that intensity training will lead to the increase of free radicals and the change of antioxidant enzymes activity, also, serum ferritin and hemoglobin concentration will decrease, red blood cell will be more fragile, hence, training will lead to more red blood cell hemolysis, and accordingly cause the loss of iron (Cao, 2004, P.1049-1052; Cao, 2004, P477-483; Cao, 2003, P331-335). Iron is one of the necessary micronutrient, and is the component of hemoglobin, myoglobin and cytochrome, which are enzymes that contain iron and are responsible for oxygen transportation and exchange as well as tissue respiration. During sport, metabolism is accelerated, and synthesis and decomposing activity will be more active, accordingly iron metabolism will be strengthened, so it is easy for athletes to lack iron after sports, the synthesis of some compounds that contain heme iron will be affected, and it is difficult for athlete to get back. Hence, athletes who take part in large intensity training for a long period time get iron deficiency anemia easily. In this study, serum iron and ferritin didn't change greatly, but showed a trend of decrease.

Erythrocyte hemoglobin distribution width 20 days after training is higher than that before training $(\mathrm{P}<0.05)$, but Erythrocyte hemoglobin distribution widths 40 days and 60 days after training are lower than that 20 days after training $(\mathrm{P}<0.05)$. Erythrocyte hemoglobin distribution width reflects the red blood cell volume, and it is usually used to diagnose early iron deficiency anemia, while iron deficiency anemia is the most common anemia of athlete. When body lacks iron and hemoglobin is normal, erythrocyte hemoglobin distribution width will be aberrant. In the training, red blood cell will be renewed fast; when the number of reticulocyte increases, erythrocyte hemoglobin distribution width will be increased (Feng, 2003, P.56-64). In addition, the break and dissolution of red blood cell should be taken into consideration, athlete should eat some nutriments, such as antioxidant, phosphatide to protect blood cell membrane, and to reduce and prevent haemolysis.

Transferrin is a globulin that has two iron ions and transfers iron in the blood, the amount of this protein can regulate the absorption of iron (Feng, 2003, P.56-64). When the iron is absorbed by body, transferrin will transport the iron to specific tissue and red blood cells, cells will make the iron as functional iron, transferrin will transport the iron to marrow, liver or spleen and make it as reserve. When the body takes in little iron or iron metabolism is accelerated, transferrin will transport the reserved iron to the cells that need iron, although there is a little transferrin, it reflects the situation of functional iron and reserved iron, and reflects the distribution of iron in the body (Cao, 2003, P. 331-335). In this study, the athletes' transferrin 20 days after training was much higher than that before training $(\mathrm{P}<0.05)$, it means that in the training, the amount of functional iron decreased, which led to the increase of transferrin. The amount of hemoglobin 40 days and 60 days after training was lower than that 20 days after training $(\mathrm{P}<0.05)$, maybe the functional iron in the blood increased after training because of the improvement of movement ability.

Serum transferrin receptor (sTfR) is a glycoprotein; it is mainly produced by marrow and reticulocyte. sTfR concentration has correlation with the proliferation of marrow red blood cell, and has negative correlation with serum iron. It is reported recently that EPO and sTfR both can reflect the hematopoietic situation, sTfR can reflect the hematopoietic activity of marrow, if both EPO and sTfR are detected, the situation of iron metabolism can be reflected, accordingly, effective training plan can be made (Abellan, et al., 2007, P. 9-15; Sharp, et al., 2002, P. 1248-57). In addition, serum transferrin receptor can reflect the situation of iron metabolism, the amount of serum transferrin receptor will increase when body lacks iron, and the red blood cell lacks iron, or when body is in the state of iron deficiency anaemia. But at different stages, the increase degrees of serum transferrin receptor are different; it means that serum transferrin receptor is a specific index to check the situation of iron (Virtanen, et al., 1999, P. 256-60). Being different from the above situation, the amount of serum transferrin receptor didn't change much in the training.

Erythropoietin (EPO) is a kind of glycoprotein hormone, its molecular weight is $34 \mathrm{kD}$, EPO in the blood is composed of 165 amino acid, and is greatly glycosylated by sialic acid. Natural EPO can be classified into two kinds according to the content of carbohydrate, $\alpha$ type contains $34 \%$ carbohydrate, $\beta$ type contains $26 \%$ carbohydrate. Two types of carbohydrate are the same in the aspects of biological characteristic, antigen and clinic effect. It is traditionally suggested EPO can act on bone marrow hematopoietic stem cells, and accelerate the proliferation, differentiation of erythroid progenitor cell. In some physical ability dependent sports, such as track and field, EPO can regulate the oxygen supply, and human body has high demand on the oxygen carrying ability of red blood cell. EPO can quickly active the expression of proto-oncogene, $c-m y c$, and maintain the life of the cell. Some experiments showed that EPO can not directly accelerate the replication of chromosome and mitosis, so EPO play important roles in anti-apoptosis, which can make red blood cell survive and differentiate into mature red blood cell (Kirito, et al., 2002, P.51-4; Kirito, et al., 1998, P.462-71). It has been proved that the production of EPO has correlation with oxygen supply, but the specific mechanism is still unclear. When the body lacks oxygen, the pressure around renal interstitial cells will decrease, which will influence the state of cytoplasm and finally lead to the increase of EPO expression. In this study, EPO level shows difference between individuals, so we analyzed the data with the method of Friedman variance analysis, it is indicated that the EPO 20 days after training was a little higher than that before training, but it was not significant, this accorded with the situation that in the beginning of training, the body lacked oxygen and the amount of hemoglobin decreased, so 
the EPO level increased. With the progress of training, EPO level decreased compared with that 20 days after training, may be this was the adaptation of body to training.

\section{Conclusion}

In the training, the hemoglobin of elite female middle-distance runners firstly decreased then increased; serum iron firstly decreased then increased, but it is not significant; serum ferritin didn't change apparently; serum transferrin firstly increased then decreased; serum transferrin receptor didn't change much in the training; the Erythrocyte hemoglobin distribution width firstly increased then decreased; EPO firstly increased then decreased in the training.

\section{References}

Abellan R, Ventura R, Pichini S, et al. (2007). Effect of physical fitness and endurance exercise on indirect biomarkers of recombinant erythropoietin misuse [J]. Int J Sports Med. 28(1): 9-15.

Cao, Jianmin. Jin, Li. Zhao, Jiexiu. Zheng, Hongrong and Tian, Ye. (2004). Effects of nutrition supplement on erythrocyte zinc protoprophyrin, transferrin receptor in rats of sports anemia. [J]. Journal of Beijing Sport University. 27 (4): 477-483.

Cao, Jianmin. Tian, Ye. Zhao, Jiexiu and Jin, Li. (2003). Exercise and iron metabolism. [J]. Journal of Beijing Sport University. 26 (3): 331-335.

Cao, Jianmin. Zhao, Jiexiu. Jin, Li. Zheng, Hongrong and Tian, Ye. (2004). Effects of nutrition supplement on erythrocyte indexes, serum iron, ferritin and transferrin in rats of sports anemia. [J]. Journal of Beijing Sport University. 27 (8): 1049-1052.

Feng, Lianshi. Feng, Meiyun and Feng, Weiquan. (2003). The functional siagnosis methods in elite athlete and problems. [M] Beijing. People's Sports Publishing House. 56-64.

Kirito K, Nagashima T, Ozawa K, et al. (2002). Constitutive activation of Stat1 and Stat3 in primary erythroleukemia cells [J]. Int J Hematol. 75 (1): 51-4.

Kirito K, Uchida M, Takatoku M, et al. (1998). A novel function of Stat1 and Stat3 proteins in erythropoietin-induced erythroid differentiation of a human leukemia cell line [J]. Blood. 92 (2): 462-71.

Sharpe K, Hopkins W, Emslie KR, et al. (2002). Development of reference ranges in elite athletes for markers of altered erythropoiesis [J]. Haematologica. 87(12): 1248-57.

Virtanen MA, Viinikka LU, Virtanen MK, et al. (1999). Higher concentrations of serum transferrin receptor in children than in adults [J]. Am J Clin Nutr, 69 (2): 256-60. 
Table 1. Content variation of red blood cell, hemoglobin, pressure and volume of blood cell, Erythrocyte hemoglobin distribution width (RDW), serum iron and serum ferritin

\begin{tabular}{|c|c|c|c|c|}
\hline & Before training & $\begin{array}{ll}\text { 20days } & \text { after } \\
\text { training } & \end{array}$ & $\begin{array}{l}\text { 40days } \\
\text { training }\end{array}$ & $\begin{array}{l}\text { 60days } \\
\text { training }\end{array}$ \\
\hline $\begin{array}{l}\text { Red blood cell } \\
\left(\times 10^{12} / \mathrm{L}\right)\end{array}$ & $4.52 \pm 0.36$ & $4.35 \pm 0.47$ & $4.21 \pm 0.21$ & $4.21 \pm 0.48$ \\
\hline $\begin{array}{l}\text { Hemoglobin } \\
(\mathrm{g} / \mathrm{dL})\end{array}$ & $12.74 \pm 1.24$ & $11.43 \pm 0.79 *$ & $13.16 \pm 1.34 \#$ & $12.84 \pm 1.34 \#$ \\
\hline $\begin{array}{l}\text { Pressure and } \\
\text { volume of blood } \\
\text { cell (\%) }\end{array}$ & $39.34 \pm 4.22$ & $35.10 \pm 2.66$ & $39.05 \pm 4.35$ & $37.44 \pm 3.79$ \\
\hline RDW (\%) & $13.16 \pm 0.87$ & $14.75 \pm 0.46^{*}$ & $12.64 \pm 0.34 \#$ & $12.66 \pm 0.30 \#$ \\
\hline $\begin{array}{l}\text { serum } \\
\text { (ug/dL) }\end{array}$ & $63.62 \pm 20.75$ & $54.70 \pm 18.29$ & $56.99 \pm 22.59$ & $57.19 \pm 21.92$ \\
\hline $\begin{array}{ll}\text { serum } & \text { ferritin } \\
(\mathrm{ng} / \mathrm{mL}) & \end{array}$ & $87.41 \pm 46.86$ & $44.49 \pm 37.52$ & $61.35 \pm 22.61$ & $67.61 \pm 33.70$ \\
\hline
\end{tabular}

$*: \mathrm{P}<0.05 * *: \mathrm{P}<0.01$ compared with the situation before training

\#: $\mathrm{P}<0.05$ \#\#: $\mathrm{P}<0.01$ compared with the situation 2 weeks after training

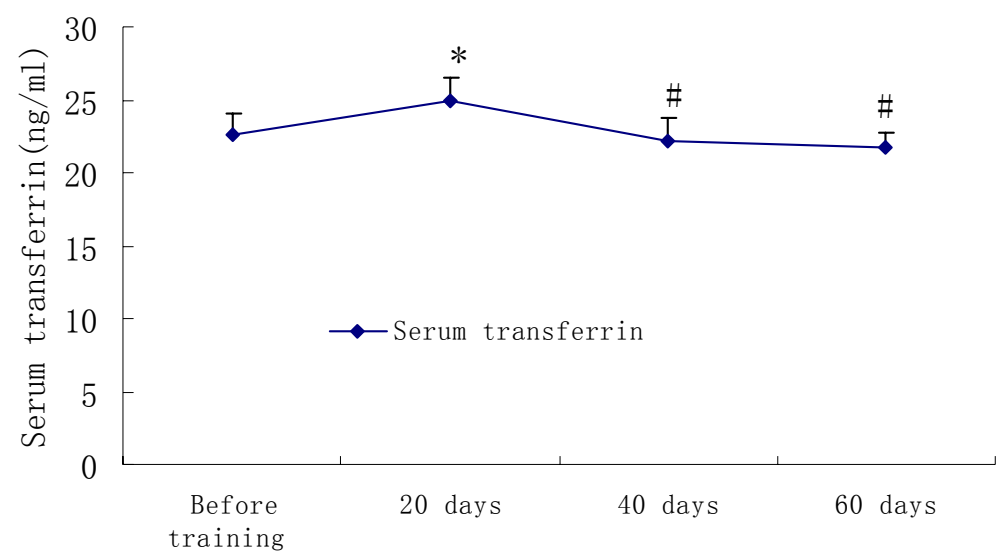

Figure 1. The variation of serum transferrin content of athletes

*: $\mathrm{P}<0.05$ **: $\mathrm{P}<0.01$ compared with the situation before training \#: $\mathrm{P}<0.05$ \#\#: $\mathrm{P}<0.01$ compared with the situation 20 days after training 


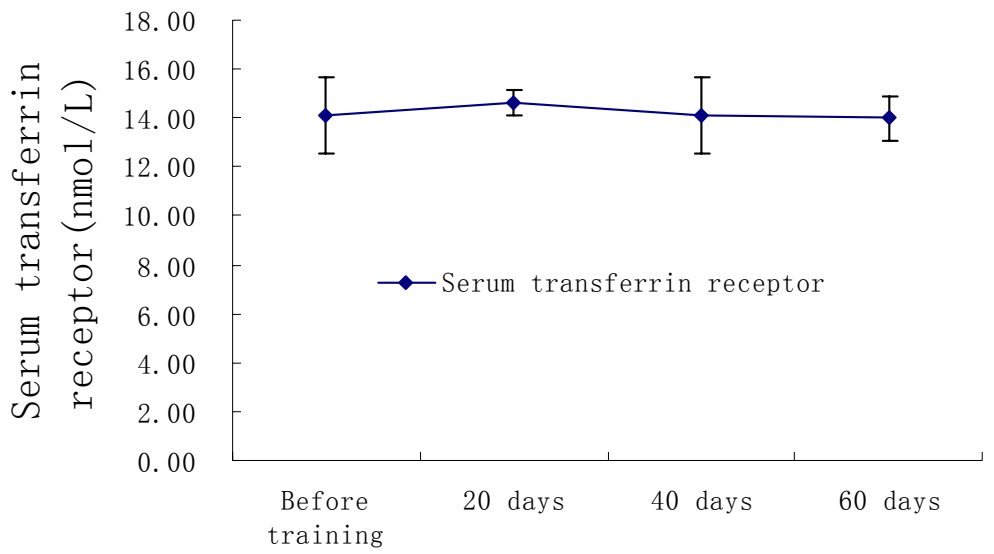

Figure 2. The variation of serum transferrin receptor content of athletes

$*: \mathrm{P}<0.05$ **: $\mathrm{P}<0.01$ compared with the situation before training \#: $\mathrm{P}<0.05$ \#\#: $\mathrm{P}<0.01$ compared with the situation in the training

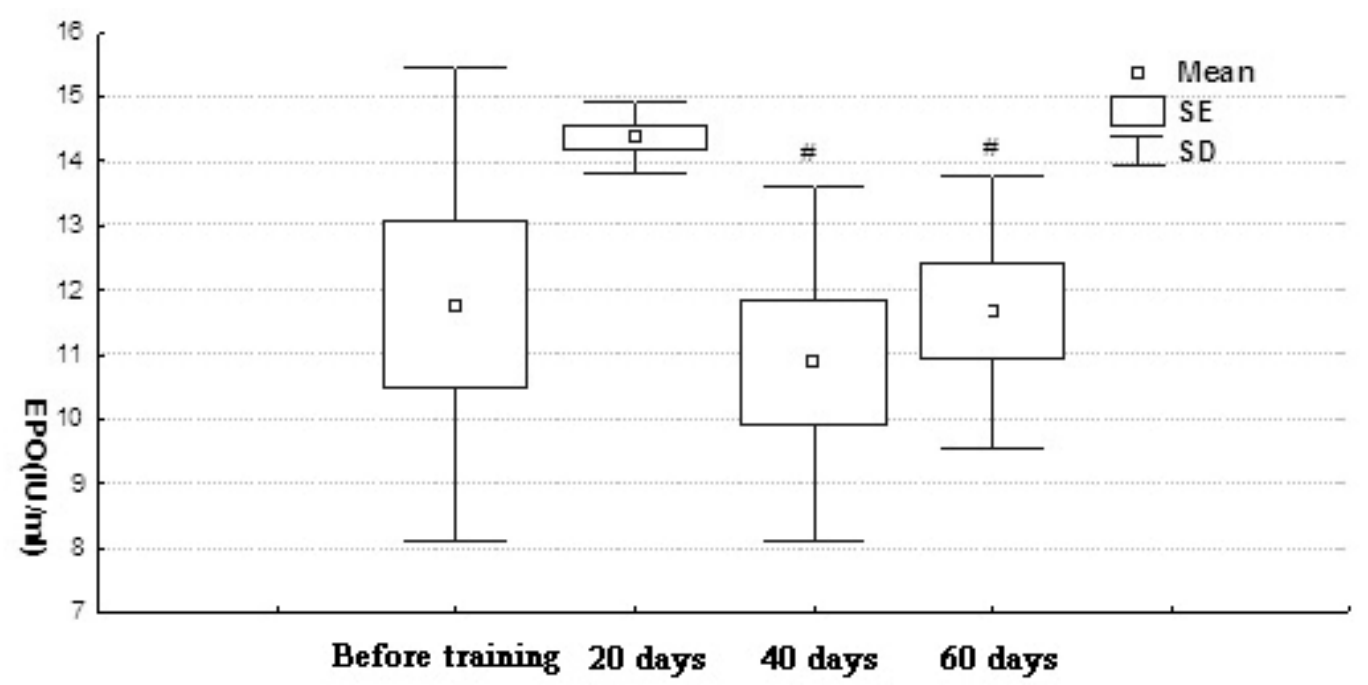

Figure 3. The variation of EPO content of athletes \#: $\mathrm{P}<0.05$ \#\#: $\mathrm{P}<0.01$ compared with the situation before training 